\title{
Iterative algorithms based on the viscosity approximation method for equilibrium and constrained convex minimization problem
}

Ming $\operatorname{Tian}^{*}$ and Lei Liu

"Correspondence:
tianming1963@126.com
College of Science, Civil Aviation
University of China, Tianjin, 300300,
China

\begin{abstract}
The gradient-projection algorithm (GPA) plays an important role in solving constrained convex minimization problems. Based on the viscosity approximation method, we combine the GPA and averaged mapping approach to propose implicit and explicit composite iterative algorithms for finding a common solution of an equilibrium and a constrained convex minimization problem for the first time in this paper. Under suitable conditions, strong convergence theorems are obtained. MSC: $46 \mathrm{~N} 10 ; 47 \mathrm{~J} 20 ; 74 \mathrm{G} 60$
\end{abstract}

Keywords: iterative algorithm; equilibrium problem; constrained convex minimization; variational inequality

\section{Introduction}

Let $H$ be a real Hilbert space with inner product $\langle\cdot, \cdot\rangle$ and norm $\|\cdot\|$. Let $C$ be a nonempty closed convex subset of $H$. Let $T: C \rightarrow C$ be a nonexpansive mapping, namely $\|T x-T y\| \leq$ $\|x-y\|$, for all $x, y \in C$. The set of fixed points of $T$ is denoted by $F(T)$.

Let $\phi$ be a bifunction of $C \times C$ into $\mathbb{R}$, where $\mathbb{R}$ is the set of real numbers. Consider the equilibrium problem (EP) which is to find $z \in C$ such that

$$
\phi(z, y) \geq 0, \quad \forall y \in C
$$

We denoted the set of solutions of $\mathrm{EP}$ by $\operatorname{EP}(\phi)$. Given a mapping $F: C \rightarrow H$, let $\phi(x, y)=$ $\langle F x, y-x\rangle$ for all $x, y \in C$, then $z \in \operatorname{EP}(\phi)$ if and only if $\langle F z, y-z\rangle \geq 0$ for all $y \in C$, that is, $z$ is a solution of the variational inequality. Numerous problems in physics, optimizations, and economics reduce to find a solution of (1.1). Some methods have been proposed to solve the equilibrium problem; see, for instance, [1-3] and the references therein.

Composite iterative algorithms were proposed by many authors for finding a common solution of an equilibrium problem and a fixed point problem (see [4-18]).

On the other hand, consider the constrained convex minimization problem as follows:

$$
\operatorname{minimize}\{g(x): x \in C\}
$$

where $g: C \rightarrow \mathbb{R}$ is a real-valued convex function. It is well known that the gradientprojection algorithm (GPA) plays an important role in solving constrained convex mini-

C 2012 Tian and Liu; licensee Springer. This is an Open Access article distributed under the terms of the Creative Commons Attribution License (http://creativecommons.org/licenses/by/2.0), which permits unrestricted use, distribution, and reproduction in any medium, provided the original work is properly cited. 
mization problems. If $g$ is (Fréchet) differentiable, then the GPA generates a sequence $\left\{x_{n}\right\}$ using the following recursive formula:

$$
x_{n+1}=P_{C}\left(x_{n}-\lambda \nabla g\left(x_{n}\right)\right), \quad \forall n \geq 0,
$$

or more generally,

$$
x_{n+1}=P_{C}\left(x_{n}-\lambda_{n} \nabla g\left(x_{n}\right)\right), \quad \forall n \geq 0,
$$

where in both (1.3) and (1.4) the initial guess $x_{0}$ is taken from $C$ arbitrarily, and the parameters, $\lambda$ or $\lambda_{n}$, are positive real numbers satisfying certain conditions. The convergence of the algorithms (1.3) and (1.4) depends on the behavior of the gradient $\nabla g$. As a matter of fact, it is known that if $\nabla g$ is $\alpha$-strongly monotone and $L$-Lipschitzian with constants $\alpha, L \geq 0$, then the operator

$$
W:=P_{C}(I-\lambda \nabla g)
$$

is a contraction; hence the sequence $\left\{x_{n}\right\}$ defined by the algorithm (1.3) converges in norm to the unique minimizer of (1.2). However, if the gradient $\nabla g$ fails to be strongly monotone, the operator $W$ defined by (1.5) would fail to be contractive; consequently, the sequence $\left\{x_{n}\right\}$ generated by the algorithm (1.3) may fail to converge strongly (see [19]). If $\nabla g$ is Lipschitzian, then the algorithms (1.3) and (1.4) can still converge in the weak topology under certain conditions.

Recently, Xu [19] proposed an explicit operator-oriented approach to the algorithm (1.4); that is, an averaged mapping approach. He gave his averaged mapping approach to the GPA (1.4) and the relaxed gradient-projection algorithm. Moreover, he constructed a counterexample which shows that the algorithm (1.3) does not converge in norm in an infinite-dimensional space and also presented two modifications of GPA which are shown to have strong convergence [20,21].

In 2011, Ceng et al. [22] proposed the following explicit iterative scheme:

$$
x_{n+1}=P_{C}\left[s_{n} \gamma V x_{n}+\left(I-s_{n} \mu F\right) T_{n} x_{n}\right], \quad n \geq 0,
$$

where $s_{n}=\frac{2-\lambda_{n} L}{4}$ and $P_{C}\left(I-\lambda_{n} \nabla g\right)=s_{n} I+\left(1-s_{n}\right) T_{n}$ for each $n \geq 0$. He proved that the sequences $\left\{x_{n}\right\}$ converge strongly to a minimizer of the constrained convex minimization problem, which also solves a certain variational inequality.

In 2000, Moudafi [2] introduced the viscosity approximation method for nonexpansive mappings, extended in [23]. Let $f$ be a contraction on $H$, starting with an arbitrary initial $x_{0} \in H$, define a sequence $\left\{x_{n}\right\}$ recursively by

$$
x_{n+1}=\alpha_{n} f\left(x_{n}\right)+\left(1-\alpha_{n}\right) T x_{n}, \quad n \geq 0,
$$

where $\left\{\alpha_{n}\right\}$ is a sequence in $(0,1) . \mathrm{Xu}[24]$ proved that if $\left\{\alpha_{n}\right\}$ satisfies certain conditions, the sequence $\left\{x_{n}\right\}$ generated by (1.6) converges strongly to the unique solution $x^{*} \in F(T)$ of the variational inequality

$$
\left\langle(I-f) x^{*}, x-x^{*}\right\rangle \geq 0, \quad \forall x \in F(T) .
$$


The purpose of the paper is to study the iterative method for finding the common solution of an equilibrium problem and a constrained convex minimization problem. Based on the viscosity approximation method, we combine the GPA and averaged mapping approach to propose implicit and explicit composite iterative method for finding the common element of the set of solutions of an equilibrium problem and the solution set of a constrained convex minimization problem. We also prove some strong convergence theorems.

\section{Preliminaries}

Throughout this paper, we always assume that $C$ is a nonempty closed convex subset of a Hilbert space $H$. We use ' $\rightarrow$ ' for weak convergence and ' $\rightarrow$ ' for strong convergence.

It is widely known that $H$ satisfies Opial's condition [25]; that is, for any sequence $\left\{x_{n}\right\}$ with $x_{n} \rightarrow x$, the inequality

$$
\liminf _{n \rightarrow \infty}\left\|x_{n}-x\right\|<\liminf _{n \rightarrow \infty}\left\|x_{n}-y\right\|
$$

holds for every $y \in H$ with $y \neq x$.

In order to solve the equilibrium problem for a bifunction $\phi: C \times C \rightarrow \mathbb{R}$, let us assume that $\phi$ satisfies the following conditions:

(A1) $\phi(x, x)=0$, for all $x \in C$;

(A2) $\phi$ is monotone, that is, $\phi(x, y)+\phi(y, x) \leq 0$ for all $x, y \in C$;

(A3) for all $x, y, z \in C, \lim _{t \downarrow 0} \phi(t z+(1-t) x, y) \leq \phi(x, y)$;

(A4) for each fixed $x \in C$, the function $y \mapsto \phi(x, y)$ is convex and lower semicontinuous.

Let us recall the following lemmas which will be useful for our paper.

Lemma 2.1 [26] Let $\phi$ be a bifunction from $C \times C$ into $\mathbb{R}$ satisfying (A1), (A2), (A3), and (A4), then for any $r>0$ and $x \in H$, there exists $z \in C$ such that

$$
\phi(z, y)+\frac{1}{r}\langle y-z, z-x\rangle \geq 0, \quad \forall y \in C .
$$

Further, if

$$
Q_{r} x=\left\{z \in C: \phi(z, y)+\frac{1}{r}\langle y-z, z-x\rangle \geq 0, \forall y \in C\right\},
$$

then the following hold:

(1) $Q_{r}$ is single-valued;

(2) $Q_{r}$ is firmly nonexpansive; that is,

$$
\left\|Q_{r} x-Q_{r} y\right\|^{2} \leq\left\langle Q_{r} x-Q_{r} y, x-y\right\rangle, \quad \forall x, y \in H ;
$$

(3) $F\left(Q_{r}\right)=\mathrm{EP}(\phi)$;

(4) $\mathrm{EP}(\phi)$ is closed and convex.

Definition 2.1 A mapping $T: H \rightarrow H$ is said to be firmly nonexpansive if and only if $2 T-I$ is nonexpansive, or equivalently,

$$
\langle x-y, T x-T y\rangle \geq\|T x-T y\|^{2}, \quad x, y \in H .
$$


Alternatively, $T$ is firmly nonexpansive if and only if $T$ can be expressed as

$$
T=\frac{1}{2}(I+S)
$$

where $S: H \rightarrow H$ is nonexpansive. Obviously, projections are firmly nonexpansive.

Definition 2.2 A mapping $T: H \rightarrow H$ is said to be an averaged mapping if it can be written as the average of the identity $I$ and a nonexpansive mapping; that is,

$$
T=(1-\alpha) I+\alpha S
$$

where $\alpha \in(0,1)$ and $S: H \rightarrow H$ is nonexpansive. More precisely, when (2.1) holds, we say that $T$ is $\alpha$-averaged.

Clearly, a firmly nonexpansive mapping is a $\frac{1}{2}$-averaged map.

Proposition 2.1 [27] For given operators $S, T, V: H \rightarrow H$ :

(i) If $T=(1-\alpha) S+\alpha V$ for some $\alpha \in(0,1)$ and if $U$ is averaged and $V$ is nonexpansive, then $T$ is averaged.

(ii) $T$ is firmly nonexpansive if and only if the complement I-T is firmly nonexpansive.

(iii) If $T=(1-\alpha) S+\alpha V$ for some $\alpha \in(0,1)$, $U$ is firmly nonexpansive and $V$ is nonexpansive, then $T$ is averaged.

(iv) The composite of finitely many averaged mappings is averaged. That is, if each of the mappings $\left\{T_{i}\right\}_{i=1}^{N}$ is averaged, then so is the composite $T_{1} \cdots T_{N}$. In particular, if $T_{1}$ is $\alpha_{1}$-averaged, and $T_{2}$ is $\alpha_{2}$-averaged, where $\alpha_{1}, \alpha_{2} \in(0,1)$, then the composite $T_{1} T_{2}$ is $\alpha$-averaged, where $\alpha=\alpha_{1}+\alpha_{2}-\alpha_{1} \alpha_{2}$.

Recall that the metric projection from $H$ onto $C$ is the mapping $P_{C}: H \rightarrow C$ which assigns, to each point $x \in H$, the unique point $P_{C} x \in C$ satisfying the property

$$
\left\|x-P_{C} x\right\|=\inf _{y \in C}\|x-y\|=: d(x, C)
$$

Lemma 2.2 For a given $x \in H$ :

(a) $z=P_{C} x$ if and only if $\langle x-z, y-z\rangle \leq 0, \forall y \in C$.

(b) $z=P_{C} x$ if and only if $\|x-z\|^{2} \leq\|x-y\|^{2}-\|y-z\|^{2}, \forall y \in C$.

(c) $\left\langle P_{C} x-P_{C} y, x-y\right\rangle \geq\left\|P_{C} x-P_{C} y\right\|^{2}, \forall x, y \in H$.

Consequently, $P_{C}$ is nonexpansive and monotone.

Lemma 2.3 The following inequality holds in an inner product space X:

$$
\|x+y\|^{2} \leq\|x\|^{2}+2\langle y, x+y\rangle, \quad \forall x, y \in X
$$

The so-called demiclosedness principle for nonexpansive mappings will be used.

Lemma 2.4 (Demiclosedness principle [28]) Let $T: C \rightarrow C$ be a nonexpansive mapping with $\operatorname{Fix}(T) \neq \varnothing$. If $\left\{x_{n}\right\}$ is a sequence in $C$ that converges weakly to $x$ and if $\left\{(I-T) x_{n}\right\}$ converges strongly to $y$, then $(I-T) x=y$. In particular, if $y=0$, then $x \in \operatorname{Fix}(T)$. 
Next, we introduce monotonicity of a nonlinear operator.

Definition 2.3 A nonlinear operator $G$ whose domain $D(G) \subseteq H$ and range $R(G) \subseteq H$ is said to be:

(a) monotone if

$$
\langle x-y, G x-G y\rangle \geq 0, \quad \forall x, y \in D(G)
$$

(b) $\beta$-strongly monotone if there exists $\beta>0$ such that

$$
\langle x-y, G x-G y\rangle \geq \beta\|x-y\|^{2}, \quad \forall x, y \in D(G),
$$

(c) $v$-inverse strongly monotone (for short, $v$-ism) if there exists $v>0$ such that

$$
\langle x-y, G x-G y\rangle \geq v\|G x-G y\|^{2}, \quad \forall x, y \in D(G) .
$$

It can be easily seen that if $G$ is nonexpansive, then $I-G$ is monotone; and the projection map $P_{C}$ is a 1-ism.

The inverse strongly monotone (also referred to as co-coercive) operators have been widely used to solve practical problems in various fields, for instance, in traffic assignment problems; see, for example, $[29,30]$ and reference therein.

The following proposition summarizes some results on the relationship between averaged mappings and inverse strongly monotone operators.

Proposition 2.2 [27] Let $T: H \rightarrow H$ be an operator from $H$ to itself.

(a) $T$ is nonexpansive if and only if the complement $I-T$ is $\frac{1}{2}$-ism.

(b) If $T$ is $v$-ism, then for $\gamma>0, \gamma T$ is $\frac{v}{\gamma}$-ism.

(c) $T$ is averaged if and only if the complement $I-T$ is $v$-ism for some $v>\frac{1}{2}$. Indeed, for $\alpha \in(0,1), T$ is $\alpha$-averaged if and only if $I-T$ is $\frac{1}{2 \alpha}$-ism.

Lemma 2.5 [24] Let $\left\{a_{n}\right\}$ be a sequence of nonnegative numbers satisfying the condition

$$
a_{n+1} \leq\left(1-\gamma_{n}\right) a_{n}+\gamma_{n} \delta_{n}, \quad \forall n \geq 0,
$$

where $\left\{\gamma_{n}\right\},\left\{\delta_{n}\right\}$ are sequences of real numbers such that:

(i) $\left\{\gamma_{n}\right\} \subset(0,1)$ and $\sum_{n=0}^{\infty} \gamma_{n}=\infty$,

(ii) $\lim \sup _{n \rightarrow \infty} \delta \leq 0$ or $\sum_{n=0}^{\infty} \gamma_{n}\left|\delta_{n}\right|<\infty$.

Then $\lim _{n \rightarrow \infty} a_{n}=0$.

\section{Main results}

In this paper, we always assume that $g: C \rightarrow \mathbb{R}$ is a real-valued convex function and $\nabla g$ is an $L$-Lipschitzian mapping with $L \geq 0$. Since the Lipschitz continuity of $\nabla g$ implies that it is indeed inverse strongly monotone, its complement can be an averaged mapping. Consequently, the GPA can be rewritten as the composite of a projection and an averaged mapping, which is again an averaged mapping. This shows that an averaged mapping plays an important role in the gradient-projection algorithm. 
Note that $\nabla g$ is $L$-Lipschitzian. This implies that $\nabla g$ is $(1 / L)$-ism, which then implies that $\lambda \nabla g$ is $(1 / \lambda L)$-ism. So, by Proposition $2.2, I-\lambda \nabla g$ is $(\lambda L / 2)$-averaged. Now since the projection $P_{C}$ is $(1 / 2)$-averaged, we see from Proposition 2.1 that the composite $P_{C}(I-$ $\lambda \nabla g)$ is $((2+\lambda L) / 4)$-averaged for $0<\lambda<2 / L$. Hence, we have that for each $n, P_{C}\left(I-\lambda_{n} \nabla g\right)$ is $\left(\left(2+\lambda_{n} L\right) / 4\right)$-averaged. Therefore, we can write

$$
P_{C}\left(I-\lambda_{n} \nabla g\right)=\frac{2-\lambda_{n} L}{4} I+\frac{2+\lambda_{n} L}{4} T_{n}=s_{n} I+\left(1-s_{n}\right) T_{n},
$$

where $T_{n}$ is nonexpansive and $s_{n}=\frac{2-\lambda_{n} L}{4}$.

Let $f: C \rightarrow C$ be a contraction with the constant $\rho \in(0,1)$. Suppose that the minimization problem (1.2) is consistent, and let $U$ denote its solution set. Let $\left\{Q_{\beta_{n}}\right\}$ be a sequence of mappings defined as in Lemma 2.1. Consider the following mapping $G_{n}$ on $C$ defined by

$$
G_{n} x=\alpha_{n} f(x)+\left(1-\alpha_{n}\right) T_{n} Q_{\beta_{n}} x, \quad x \in C, n \in \mathbb{N},
$$

where $\alpha_{n} \in(0,1)$. By Lemma 2.1, we have

$$
\left\|G_{n} x-G_{n} y\right\| \leq\left(1-\alpha_{n}(1-\rho)\right)\|x-y\| .
$$

Since $0<1-\alpha_{n}(1-\rho)<1$, it follows that $G_{n}$ is a contraction. Therefore, by the Banach contraction principle, $G_{n}$ has a unique fixed point $x_{n}^{f} \in C$ such that

$$
x_{n}^{f}=\alpha_{n} f\left(x_{n}^{f}\right)+\left(1-\alpha_{n}\right) T_{n} Q_{\beta_{n}} x_{n}^{f} .
$$

For simplicity, we will write $x_{n}$ for $x_{n}^{f}$ provided no confusion occurs. Next, we prove the convergence of $\left\{x_{n}\right\}$, while we claim the existence of the $q \in U \cap \operatorname{EP}(\phi)$, which solves the variational inequality

$$
\langle(I-f) q, p-q\rangle \geq 0, \quad \forall p \in U \cap \operatorname{EP}(\phi) .
$$

Equivalently, $q=P_{U \cap E P(\phi)} f(q)$.

Theorem 3.1 Let $C$ be a nonempty closed convex subset of a real Hilbert space $H$ and $\phi$ be a bifunction from $C \times C$ into $\mathbb{R}$ satisfying (A1), (A2), (A3), and (A4). Let $g: C \rightarrow \mathbb{R}$ be a real-valued convex function, and assume that $\nabla g$ is an L-Lipschitzian mapping with $L \geq 0$ and $f: C \rightarrow C$ is a contraction with the constant $\rho \in(0,1)$. Assume that $U \cap \operatorname{EP}(\phi) \neq \emptyset$. Let $\left\{x_{n}\right\}$ be a sequence generated by

$$
\left\{\begin{array}{l}
\phi\left(u_{n}, y\right)+\frac{1}{\beta_{n}}\left\langle y-u_{n}, u_{n}-x_{n}\right\rangle \geq 0, \quad \forall y \in C, \\
x_{n}=\alpha_{n} f\left(x_{n}\right)+\left(1-\alpha_{n}\right) T_{n} u_{n}, \quad \forall n \in \mathbb{N},
\end{array}\right.
$$

where $u_{n}=Q_{\beta_{n}} x_{n}, P_{C}\left(I-\lambda_{n} \nabla g\right)=s_{n} I+\left(1-s_{n}\right) T_{n}, s_{n}=\frac{2-\lambda_{n} L}{4}$ and $\left\{\lambda_{n}\right\} \subset\left(0, \frac{2}{L}\right)$. Let $\left\{\beta_{n}\right\}$ and $\left\{\alpha_{n}\right\}$ satisfy the following conditions: 
(i) $\left\{\beta_{n}\right\} \subset(0, \infty), \liminf _{n \rightarrow \infty} \beta_{n}>0$;

(ii) $\left\{\alpha_{n}\right\} \subset(0,1), \lim _{n \rightarrow \infty} \alpha_{n}=0$.

Then $\left\{x_{n}\right\}$ converges strongly, as $s_{n} \rightarrow 0\left(\Leftrightarrow \lambda_{n} \rightarrow \frac{2}{L}\right)$, to a point $q \in U \cap \operatorname{EP}(\phi)$ which solves the variational inequality (3.1).

Proof First, we claim that $\left\{x_{n}\right\}$ is bounded. Indeed, pick any $p \in U \cap \operatorname{EP}(\phi)$, since $u_{n}=$ $Q_{\beta_{n}} x_{n}$ and $p=Q_{\beta_{n}} p$, then we know that for any $n \in \mathbb{N}$,

$$
\left\|u_{n}-p\right\|=\left\|Q_{\beta_{n}} x_{n}-Q_{\beta_{n}} p\right\| \leq\left\|x_{n}-p\right\| .
$$

Thus, we derive that (noting $T_{n} p=p$ and $T_{n}$ is nonexpansive)

$$
\begin{aligned}
\left\|x_{n}-p\right\| & =\left\|\alpha_{n} f\left(x_{n}\right)+\left(1-\alpha_{n}\right) T_{n} u_{n}-p\right\| \\
& \leq\left\|\alpha_{n} f\left(x_{n}\right)-\alpha_{n} f(p)\right\|+\left\|\alpha_{n} f(p)-\alpha_{n} p\right\|+\left(1-\alpha_{n}\right)\left\|T_{n} u_{n}-T_{n} p\right\| \\
& \leq\left[1-\alpha_{n}(1-\rho)\right]\left\|x_{n}-p\right\|+\alpha_{n}\|(I-f) p\| .
\end{aligned}
$$

Then we have

$$
\left\|x_{n}-p\right\| \leq \frac{1}{1-\rho}\|(I-f) p\|
$$

and hence $\left\{x_{n}\right\}$ is bounded. From (3.2), we also derive that $\left\{u_{n}\right\}$ is bounded.

Next, we claim that $\left\|x_{n}-u_{n}\right\| \rightarrow 0$. Indeed, for any $p \in U \cap \operatorname{EP}(\phi)$, by Lemma 2.1 , we have

$$
\begin{aligned}
\left\|u_{n}-p\right\|^{2} & =\left\|Q_{\beta_{n}} x_{n}-Q_{\beta_{n}} p\right\|^{2} \\
& \leq\left\langle x_{n}-p, u_{n}-p\right\rangle \\
& =\frac{1}{2}\left(\left\|x_{n}-p\right\|^{2}+\left\|u_{n}-p\right\|^{2}-\left\|u_{n}-x_{n}\right\|^{2}\right) .
\end{aligned}
$$

This implies that

$$
\left\|u_{n}-p\right\|^{2} \leq\left\|x_{n}-p\right\|^{2}-\left\|u_{n}-x_{n}\right\|^{2} .
$$

Then from (3.3), we derive that

$$
\begin{aligned}
\left\|x_{n}-p\right\|^{2} & =\left\|\alpha_{n} f\left(x_{n}\right)+\left(1-\alpha_{n}\right) T_{n} u_{n}-p\right\|^{2} \\
& =\left\|\alpha_{n} f\left(x_{n}\right)-\alpha_{n} p+\left(1-\alpha_{n}\right) T_{n} u_{n}-\left(1-\alpha_{n}\right) T_{n} p\right\|^{2} \\
& \leq\left(1-\alpha_{n}\right)^{2}\left\|u_{n}-p\right\|^{2}+2 \alpha_{n}\left(f\left(x_{n}\right)-p, x_{n}-p\right\rangle \\
& \leq\left\|x_{n}-p\right\|^{2}-\left\|u_{n}-x_{n}\right\|^{2}+2 \alpha_{n}\left[\rho\left\|x_{n}-p\right\|+\|(I-f) p\|\right]\left\|x_{n}-p\right\| .
\end{aligned}
$$

Since $\alpha_{n} \rightarrow 0$, it follows that

$$
\lim _{n \rightarrow \infty}\left\|x_{n}-u_{n}\right\|=0
$$


Then we show that $\left\|x_{n}-T_{n} x_{n}\right\| \rightarrow 0$. Indeed,

$$
\begin{aligned}
\left\|x_{n}-T_{n} x_{n}\right\| & =\left\|x_{n}-T_{n} u_{n}+T_{n} u_{n}-T_{n} x_{n}\right\| \\
& \leq\left\|x_{n}-T_{n} u_{n}\right\|+\left\|T_{n} u_{n}-T_{n} x_{n}\right\| \\
& \leq \alpha_{n}\left\|f\left(x_{n}\right)-T_{n} u_{n}\right\|+\left\|u_{n}-x_{n}\right\| .
\end{aligned}
$$

Since $\alpha_{n} \rightarrow 0$ and $\left\|x_{n}-u_{n}\right\| \rightarrow 0$, we obtain that

$$
\left\|x_{n}-T_{n} x_{n}\right\| \rightarrow 0
$$

Thus,

$$
\begin{aligned}
\left\|u_{n}-T_{n} u_{n}\right\| & =\left\|u_{n}-x_{n}+x_{n}-T_{n} x_{n}+T_{n} x_{n}-T_{n} u_{n}\right\| \\
& \leq\left\|u_{n}-x_{n}\right\|+\left\|x_{n}-T_{n} x_{n}\right\|+\left\|T_{n} x_{n}-T_{n} u_{n}\right\| \\
& \leq\left\|u_{n}-x_{n}\right\|+\left\|x_{n}-T_{n} x_{n}\right\|+\left\|x_{n}-u_{n}\right\|
\end{aligned}
$$

and

$$
\left\|x_{n}-T_{n} u_{n}\right\| \leq\left\|x_{n}-u_{n}\right\|+\left\|u_{n}-T_{n} u_{n}\right\|
$$

we have

$$
\left\|u_{n}-T_{n} u_{n}\right\| \rightarrow 0 \quad \text { and } \quad\left\|x_{n}-T_{n} u_{n}\right\| \rightarrow 0 \text {. }
$$

Observe that

$$
\begin{aligned}
\left\|P_{C}\left(I-\lambda_{n} \nabla g\right) u_{n}-u_{n}\right\| & =\left\|s_{n} u_{n}+\left(1-s_{n}\right) T_{n} u_{n}-u_{n}\right\| \\
& =\left(1-s_{n}\right)\left\|T_{n} u_{n}-u_{n}\right\| \\
& \leq\left\|T_{n} u_{n}-u_{n}\right\|,
\end{aligned}
$$

where $s_{n}=\frac{2-\lambda_{n} L}{4} \in\left(0, \frac{1}{2}\right)$. Hence, we have

$$
\begin{aligned}
& \left\|P_{C}\left(I-\frac{2}{L} \nabla g\right) u_{n}-u_{n}\right\| \\
& \leq\left\|P_{C}\left(I-\frac{2}{L} \nabla g\right) u_{n}-P_{C}\left(I-\lambda_{n} \nabla g\right) u_{n}\right\|+\left\|P_{C}\left(I-\lambda_{n} \nabla g\right) u_{n}-u_{n}\right\| \\
& \leq\left\|\left(I-\frac{2}{L} \nabla g\right) u_{n}-\left(I-\lambda_{n} \nabla g\right) u_{n}\right\|+\left\|P_{C}\left(I-\lambda_{n} \nabla g\right) u_{n}-u_{n}\right\| \\
& \leq\left(\frac{2}{L}-\lambda_{n}\right)\left\|\nabla g\left(u_{n}\right)\right\|+\left\|T_{n} u_{n}-u_{n}\right\| .
\end{aligned}
$$

From the boundedness of $\left\{u_{n}\right\}, s_{n} \rightarrow 0\left(\Leftrightarrow \lambda_{n} \rightarrow \frac{2}{L}\right)$ and $\left\|u_{n}-T_{n} u_{n}\right\| \rightarrow 0$, we conclude that

$$
\lim _{n \rightarrow \infty}\left\|u_{n}-P_{C}\left(I-\frac{2}{L} \nabla g\right) u_{n}\right\|=0 .
$$


Since $\nabla g$ is $L$-Lipschitzian, $\nabla g$ is $\frac{1}{L}$-ism. Consequently, $P_{C}\left(I-\frac{2}{L} \nabla g\right)$ is a nonexpansive self-mapping on $C$. As a matter of fact, we have for each $x, y \in C$

$$
\begin{aligned}
& \left\|P_{C}\left(I-\frac{2}{L} \nabla g\right) x-P_{C}\left(I-\frac{2}{L} \nabla g\right) y\right\|^{2} \\
& \quad \leq\left\|\left(I-\frac{2}{L} \nabla g\right) x-\left(I-\frac{2}{L} \nabla g\right) y\right\|^{2} \\
& =\left\|x-y-\frac{2}{L}(\nabla g(x)-\nabla g(y))\right\|^{2} \\
& =\|x-y\|^{2}-\frac{4}{L}\langle x-y, \nabla g(x)-\nabla g(y)\rangle+\frac{4}{L^{2}}\|\nabla g(x)-\nabla g(y)\|^{2} \\
& \quad \leq\|x-y\|^{2}-\frac{4}{L^{2}}\|\nabla g(x)-\nabla g(y)\|^{2}+\frac{4}{L^{2}}\|\nabla g(x)-\nabla g(y)\|^{2} \\
& \quad=\|x-y\|^{2} .
\end{aligned}
$$

Consider a subsequence $\left\{u_{n_{i}}\right\}$ of $\left\{u_{n}\right\}$. Since $\left\{u_{n_{i}}\right\}$ is bounded, there exists a subsequence $\left\{u_{n_{i j}}\right\}$ of $\left\{u_{n_{i}}\right\}$ which converges weakly to $q$. Next, we show that $q \in U \cap \operatorname{EP}(\phi)$. Without loss of generality, we can assume that $u_{n_{i}} \rightarrow q$. Then, by Lemma 2.4, we obtain

$$
q=P_{C}\left(I-\frac{2}{L} \nabla g\right) q
$$

This shows that $q \in U$.

Next, we show that $q \in \operatorname{EP}(\phi)$. Since $u_{n}=Q_{\beta_{n}} x_{n}$, for any $y \in C$, we obtain

$$
\phi\left(u_{n}, y\right)+\frac{1}{\beta_{n}}\left\langle y-u_{n}, u_{n}-x_{n}\right\rangle \geq 0 .
$$

From (A2), we have

$$
\frac{1}{\beta_{n}}\left\langle y-u_{n}, u_{n}-x_{n}\right\rangle \geq \phi\left(y, u_{n}\right)
$$

Replacing $n$ by $n_{i}$, we have

$$
\left\langle y-u_{n_{i}}, \frac{u_{n_{i}}-x_{n_{i}}}{\beta_{n_{i}}}\right\rangle \geq \phi\left(y, u_{n_{i}}\right) .
$$

Since $\frac{u_{n_{i}}-x_{n_{i}}}{\beta_{n_{i}}} \rightarrow 0$ and $u_{n_{i}} \rightarrow q$, it follows from (A4) that $0 \geq \phi(y, q)$ for all $y \in C$. Let

$$
z_{t}=t y+(1-t) q, \quad \forall t \in(0,1], y \in C
$$

then we have $z_{t} \in C$ and hence $\phi\left(z_{t}, q\right) \leq 0$. Thus, from (A1) and (A4), we have

$$
\begin{aligned}
0 & =\phi\left(z_{t}, z_{t}\right) \\
& \leq t \phi\left(z_{t}, y\right)+(1-t) \phi\left(z_{t}, q\right) \\
& \leq t \phi\left(z_{t}, y\right)
\end{aligned}
$$


and hence $0 \leq \phi\left(z_{t}, y\right)$. From (A3), we have $0 \leq \phi(q, y)$ for all $y \in C$ and hence $q \in \operatorname{EP}(\phi)$. Therefore, $q \in \operatorname{EP}(\phi) \cap U$.

On the other hand, we note that

$$
\begin{aligned}
x_{n}-q & =\alpha_{n} f\left(x_{n}\right)+\left(1-\alpha_{n}\right) T_{n} u_{n}-q \\
& =\alpha_{n} f\left(x_{n}\right)-\alpha_{n} f(q)+\alpha_{n} f(q)-\alpha_{n} q+\left(1-\alpha_{n}\right)\left(T_{n} u_{n}-q\right) .
\end{aligned}
$$

Hence, we obtain

$$
\begin{aligned}
\left\|x_{n}-q\right\|^{2}= & \alpha_{n}\left\langle(f-I) q, x_{n}-q\right\rangle \\
& +\left\langle\alpha_{n}\left(f\left(x_{n}\right)-f(q)\right)+\left(1-\alpha_{n}\right)\left(T_{n} u_{n}-T_{n} q\right), x_{n}-q\right\rangle \\
\leq & \alpha_{n}\left\langle(f-I) q, x_{n}-q\right\rangle+\left(1-\alpha_{n}(1-\rho)\right)\left\|x_{n}-q\right\|^{2} .
\end{aligned}
$$

It follows that

$$
\left\|x_{n}-q\right\|^{2} \leq \frac{1}{1-\rho}\left\langle(f-I) q, x_{n}-q\right\rangle .
$$

In particular,

$$
\left\|x_{n_{i}}-q\right\|^{2} \leq \frac{1}{1-\rho}\left\langle(f-I) q, x_{n_{i}}-q\right\rangle .
$$

Since $x_{n_{i}} \rightarrow q$, it follows from (3.4) that $x_{n_{i}} \rightarrow q$ as $i \rightarrow \infty$.

Next, we show that $q$ solves the variational inequality (3.1). Observe that

$$
x_{n}=\alpha_{n} f\left(x_{n}\right)+\left(1-\alpha_{n}\right) T_{n} u_{n}=\alpha_{n} f\left(x_{n}\right)+\left(1-\alpha_{n}\right) T_{n} Q_{\beta_{n}} x_{n} .
$$

Hence, we conclude that

$$
(I-f) x_{n}=-\frac{1}{\alpha_{n}}\left(I-T_{n} Q_{\beta_{n}}\right) x_{n}-T_{n} Q_{\beta_{n}} x_{n}+x_{n} .
$$

Since $T_{n}$ is nonexpansive, we have that $I-T_{n} Q_{\beta_{n}}$ is monotone. Note that for any given $z \in U \cap \operatorname{EP}(\phi)$,

$$
\begin{aligned}
& \left\langle(I-f) x_{n}, x_{n}-z\right\rangle \\
& \quad=-\frac{1}{\alpha_{n}}\left\langle\left(I-T_{n} Q_{\beta_{n}}\right) x_{n}-\left(I-T_{n} Q_{\beta_{n}}\right) z, x_{n}-z\right\rangle-\left\langle T_{n} u_{n}-x_{n}, x_{n}-z\right\rangle \\
& \quad \leq\left\|T_{n} u_{n}-x_{n}\right\|\left\|x_{n}-z\right\| .
\end{aligned}
$$

Now, replacing $n$ with $n_{i}$ in the above inequality, and letting $i \rightarrow \infty$, we have

$$
\langle(I-f) q, q-z\rangle=\lim _{i \rightarrow \infty}\left\langle(I-f) x_{n_{i}}, x_{n_{i}}-z\right\rangle \leq 0 .
$$

From the arbitrariness of $z \in U \cap \operatorname{EP}(\phi)$, it follows that $q \in U \cap \mathrm{EP}(\phi)$ is a solution of the variational inequality (3.1). Further, by the uniqueness of solution of the variational 
inequality (3.1), we conclude that $x_{n} \rightarrow q$ as $n \rightarrow \infty$. The variational inequality (3.1) can be written as

$$
\langle f(q)-q, q-z\rangle \geq 0, \quad \forall z \in U \cap \mathrm{EP}(\phi) .
$$

So, in terms of Lemma 2.2, it is equivalent to the following equality:

$$
P_{U \cap \mathrm{EP}(\phi)} f(q)=q
$$

This completes the proof.

Theorem 3.2 Let $C$ be a nonempty closed convex subset of a real Hilbert space $H$ and $\phi$ be a bifunction from $C \times C$ into $\mathbb{R}$ satisfying (A1), (A2), (A3), and (A4). Let $g: C \rightarrow \mathbb{R}$ be a real-valued convex function, and assume that $\nabla g$ is an L-Lipschitzian mapping with $L \geq 0$ and $f: C \rightarrow C$ is a contraction with the constant $\rho \in(0,1)$. Assume that $U \cap \operatorname{EP}(\phi) \neq \emptyset$. Let $\left\{x_{n}\right\}$ be a sequence generated by $x_{1} \in C$ and

$$
\left\{\begin{array}{l}
\phi\left(u_{n}, y\right)+\frac{1}{\beta_{n}}\left\langle y-u_{n}, u_{n}-x_{n}\right\rangle \geq 0, \quad \forall y \in C, \\
x_{n+1}=\alpha_{n} f\left(x_{n}\right)+\left(1-\alpha_{n}\right) T_{n} u_{n}, \quad \forall n \in \mathbb{N},
\end{array}\right.
$$

where $u_{n}=Q_{\beta_{n}} x_{n}, P_{C}\left(I-\lambda_{n} \nabla g\right)=s_{n} I+\left(1-s_{n}\right) T_{n}, s_{n}=\frac{2-\lambda_{n} L}{4}$ and $\left\{\lambda_{n}\right\} \subset\left(0, \frac{2}{L}\right)$. Let $\left\{\alpha_{n}\right\}$, $\left\{\beta_{n}\right\}$ and $\left\{s_{n}\right\}$ satisfy the following conditions:

(i) $\left\{\beta_{n}\right\} \subset(0, \infty)$, $\liminf \beta_{n}>0, \sum_{n=1}^{\infty}\left|\beta_{n+1}-\beta_{n}\right|<\infty$;

(ii) $\left\{\alpha_{n}\right\} \subset(0,1), \lim _{n \rightarrow \infty} \alpha_{n}=0, \sum_{n=1}^{\infty} \alpha_{n}=\infty, \sum_{n=1}^{\infty}\left|\alpha_{n+1}-\alpha_{n}\right|<\infty$;

(iii) $\left\{s_{n}\right\} \subset\left(0, \frac{1}{2}\right), \lim _{n \rightarrow \infty} s_{n}=0\left(\Leftrightarrow \lim _{n \rightarrow \infty} \lambda_{n}=\frac{2}{L}\right), \sum_{n=1}^{\infty}\left|s_{n+1}-s_{n}\right|<\infty$.

Then $\left\{x_{n}\right\}$ converges strongly to a point $q \in U \cap \mathrm{EP}(\phi)$ which solves the variational inequality (3.1).

Proof First, we show that $\left\{x_{n}\right\}$ is bounded. Indeed, pick any $p \in U \cap \mathrm{EP}(\phi)$, since $u_{n}=Q_{\beta_{n}} x_{n}$ and $p=Q_{\beta_{n}} p$, then we know that for any $n \in \mathbb{N}$,

$$
\left\|u_{n}-p\right\|=\left\|Q_{\beta_{n}} x_{n}-Q_{\beta_{n}} p\right\| \leq\left\|x_{n}-p\right\| .
$$

Thus, we derive that (noting $T_{n} p=p$ and $T_{n}$ is nonexpansive)

$$
\begin{aligned}
\left\|x_{n+1}-p\right\| & =\left\|\alpha_{n} f\left(x_{n}\right)+\left(1-\alpha_{n}\right) T_{n} u_{n}-p\right\| \\
& \leq \alpha_{n} \rho\left\|x_{n}-p\right\|+\left(1-\alpha_{n}\right)\left\|x_{n}-p\right\|+\alpha_{n}\|f(p)-p\| \\
& \leq\left(1-\alpha_{n}(1-\rho)\right)\left\|x_{n}-p\right\|+\alpha_{n}\|f(p)-p\| .
\end{aligned}
$$

By induction, we have

$$
\left\|x_{n}-p\right\| \leq \max \left\{\left\|x_{1}-p\right\|, \frac{1}{1-\rho}\|f(p)-p\|\right\}
$$

and hence $\left\{x_{n}\right\}$ is bounded. From (3.5), we also derive that $\left\{u_{n}\right\}$ is bounded. 
Next, we show that $\left\|x_{n+1}-x_{n}\right\| \rightarrow 0$. Indeed, since $\nabla g$ is $\frac{1}{L}$-ism, $P_{C}\left(I-\lambda_{n} \nabla g\right)$ is nonexpansive. It follows that for any given $p \in S$,

$$
\begin{aligned}
\left\|P_{C}\left(I-\lambda_{n} \nabla g\right) u_{n-1}\right\| & \leq\left\|P_{C}\left(I-\lambda_{n} \nabla g\right) u_{n-1}-p\right\|+\|p\| \\
& \leq\left\|P_{C}\left(I-\lambda_{n} \nabla g\right) u_{n-1}-P_{C}\left(I-\lambda_{n} \nabla g\right) p\right\|+\|p\| \\
& \leq\left\|u_{n-1}-p\right\|+\|p\| \\
& \leq\left\|u_{n-1}\right\|+2\|p\| .
\end{aligned}
$$

This together with the boundedness of $\left\{u_{n}\right\}$ implies that $\left\{P_{C}\left(I-\lambda_{n} \nabla g\right) u_{n-1}\right\}$ is bounded.

Also, observe that

$$
\begin{aligned}
\| & T_{n} u_{n-1}-T_{n-1} u_{n-1} \| \\
= & \left\|\frac{4 P_{C}\left(I-\lambda_{n} \nabla g\right)-\left(2-\lambda_{n} L\right) I}{2+\lambda_{n} L} u_{n-1}-\frac{4 P_{C}\left(I-\lambda_{n-1} \nabla g\right)-\left(2-\lambda_{n-1} L\right) I}{2+\lambda_{n-1} L} u_{n-1}\right\| \\
\leq & \left\|\frac{4 P_{C}\left(I-\lambda_{n} \nabla g\right)}{2+\lambda_{n} L} u_{n-1}-\frac{4 P_{C}\left(I-\lambda_{n-1} \nabla g\right)}{2+\lambda_{n-1} L} u_{n-1}\right\|+\left\|\frac{2-\lambda_{n-1} L}{2+\lambda_{n-1} L} u_{n-1}-\frac{2-\lambda_{n} L}{2+\lambda_{n} L} u_{n-1}\right\| \\
= & \left\|\frac{4\left(2+\lambda_{n-1} L\right) P_{C}\left(I-\lambda_{n} \nabla g\right) u_{n-1}-4\left(2+\lambda_{n} L\right) P_{C}\left(I-\lambda_{n-1} \nabla g\right) u_{n-1} \|}{\left(2+\lambda_{n} L\right)\left(2+\lambda_{n-1} L\right)}\right\| \\
& +\frac{4 L\left|\lambda_{n}-\lambda_{n-1}\right|}{\left(2+\lambda_{n-1} L\right)\left(2+\lambda_{n} L\right)}\left\|u_{n-1}\right\| \\
\leq & \| \frac{4 L\left(\lambda_{n-1}-\lambda_{n}\right) P_{C}\left(I-\lambda_{n} \nabla g\right) u_{n-1}}{\left(2+\lambda_{n} L\right)\left(2+\lambda_{n-1} L\right)} \\
& +\frac{4\left(2+\lambda_{n} L\right)\left(P_{C}\left(I-\lambda_{n} \nabla g\right)-P_{C}\left(I-\lambda_{n-1} \nabla g\right)\right) u_{n-1} \|}{\left(2+\lambda_{n} L\right)\left(2+\lambda_{n-1} L\right)} \| \\
& +\frac{4 L\left|\lambda_{n}-\lambda_{n-1}\right|}{\left(2+\lambda_{n-1} L\right)\left(2+\lambda_{n} L\right)}\left\|u_{n-1}\right\| \\
\leq & \frac{4 L\left|\lambda_{n-1}-\lambda_{n}\right| \cdot\left\|P_{C}\left(I-\lambda_{n} \nabla g\right) u_{n-1}\right\|}{\left(2+\lambda_{n} L\right)\left(2+\lambda_{n-1} L\right)} \\
& +\frac{4\left(2+\lambda_{n} L\right)\left\|P_{C}\left(I-\lambda_{n} \nabla g\right) u_{n-1}-P_{C}\left(I-\lambda_{n-1} \nabla g\right) u_{n-1}\right\|}{\left(2+\lambda_{n} L\right)\left(2+\lambda_{n-1} L\right)} \\
& +\frac{4 L\left|\lambda_{n}-\lambda_{n-1}\right|}{\left(2+\lambda_{n-1} L\right)\left(2+\lambda_{n} L\right)}\left\|u_{n-1}\right\| \\
\leq & \left|\lambda_{n-1}-\lambda_{n}\right| \cdot\left[L\left\|P_{C}\left(I-\lambda_{n} \nabla g\right) u_{n-1}\right\|+4\left\|\nabla g\left(u_{n-1}\right)\right\|+L\left\|u_{n-1}\right\|\right] \\
\leq & M_{1}\left|\lambda_{n-1}-\lambda_{n}\right|
\end{aligned}
$$

for some appropriate constant $M_{1}>0$ such that

$$
M_{1} \geq L\left\|P_{C}\left(I-\lambda_{n} \nabla g\right) u_{n-1}\right\|+4\left\|\nabla g\left(u_{n-1}\right)\right\|+L\left\|u_{n-1}\right\|, \quad \forall n \geq 1 .
$$

Thus, we get

$$
\begin{aligned}
& \left\|x_{n+1}-x_{n}\right\| \\
& \quad=\left\|\alpha_{n} f\left(x_{n}\right)+\left(1-\alpha_{n}\right) T_{n} u_{n}-\left(\alpha_{n-1} f\left(x_{n-1}\right)+\left(1-\alpha_{n-1}\right) T_{n-1} u_{n-1}\right)\right\|
\end{aligned}
$$




$$
\begin{aligned}
= & \| \alpha_{n} f\left(x_{n}\right)-\alpha_{n} f\left(x_{n-1}\right)+\alpha_{n} f\left(x_{n-1}\right)-\alpha_{n-1} f\left(x_{n-1}\right)+\left(1-\alpha_{n}\right) T_{n} u_{n} \\
& -\left(1-\alpha_{n}\right) T_{n} u_{n-1}+\left(1-\alpha_{n}\right) T_{n} u_{n-1}-\left(1-\alpha_{n}\right) T_{n-1} u_{n-1} \\
& +\left(1-\alpha_{n}\right) T_{n-1} u_{n-1}-\left(1-\alpha_{n-1}\right) T_{n-1} u_{n-1} \| \\
\leq & \alpha_{n} \rho\left\|x_{n}-x_{n-1}\right\|+\left|\alpha_{n}-\alpha_{n-1}\right|\left\|f\left(x_{n-1}\right)\right\|+\left(1-\alpha_{n}\right)\left\|u_{n}-u_{n-1}\right\| \\
& +\left(1-\alpha_{n}\right)\left\|T_{n} u_{n-1}-T_{n-1} u_{n-1}\right\|+\left|\alpha_{n}-\alpha_{n-1}\right|\left\|T_{n-1} u_{n-1}\right\| \\
= & \alpha_{n} \rho\left\|x_{n}-x_{n-1}\right\|+\left(1-\alpha_{n}\right)\left\|u_{n}-u_{n-1}\right\|+\left(1-\alpha_{n}\right)\left\|T_{n} u_{n-1}-T_{n-1} u_{n-1}\right\| \\
& +\left|\alpha_{n}-\alpha_{n-1}\right|\left(\left\|f\left(x_{n-1}\right)\right\|+\left\|T_{n-1} u_{n-1}\right\|\right) \\
\leq & \alpha_{n} \rho\left\|x_{n}-x_{n-1}\right\|+\left(1-\alpha_{n}\right)\left\|u_{n}-u_{n-1}\right\|+M_{1}\left|\lambda_{n}-\lambda_{n-1}\right| \\
& +\left|\alpha_{n}-\alpha_{n-1}\right|\left(\left\|f\left(x_{n-1}\right)\right\|+\left\|T_{n-1} u_{n-1}\right\|\right) \\
= & \alpha_{n} \rho\left\|x_{n}-x_{n-1}\right\|+\left(1-\alpha_{n}\right)\left\|u_{n}-u_{n-1}\right\|+\left|s_{n}-s_{n-1}\right| \frac{4 M_{1}}{L} \\
& +\left|\alpha_{n}-\alpha_{n-1}\right|\left(\left\|f\left(x_{n-1}\right)\right\|+\left\|T_{n-1} u_{n-1}\right\|\right) \\
\leq & \alpha_{n} \rho\left\|x_{n}-x_{n-1}\right\|+\left(1-\alpha_{n}\right)\left\|u_{n}-u_{n-1}\right\|+M_{2}\left(\left|\alpha_{n}-\alpha_{n-1}\right|+\left|s_{n}-s_{n-1}\right|\right)
\end{aligned}
$$

for some appropriate constant $M_{2}>0$ such that

$$
M_{2} \geq \max \left\{\left\|f\left(x_{n-1}\right)\right\|+\left\|T_{n-1} u_{n-1}\right\|, \frac{4 M_{1}}{L}\right\}, \quad \forall n \geq 1 .
$$

From $u_{n+1}=Q_{\beta_{n+1}} x_{n+1}$ and $u_{n}=Q_{\beta_{n}} x_{n}$, we note that

$$
\phi\left(u_{n+1}, y\right)+\frac{1}{\beta_{n+1}}\left\langle y-u_{n+1}, u_{n+1}-x_{n+1}\right\rangle \geq 0, \quad \forall y \in C,
$$

and

$$
\phi\left(u_{n}, y\right)+\frac{1}{\beta_{n}}\left\langle y-u_{n}, u_{n}-x_{n}\right\rangle \geq 0, \quad \forall y \in C .
$$

Putting $y=u_{n}$ in (3.7) and $y=u_{n+1}$ in (3.8), we have

$$
\phi\left(u_{n+1}, u_{n}\right)+\frac{1}{\beta_{n+1}}\left\langle u_{n}-u_{n+1}, u_{n+1}-x_{n+1}\right\rangle \geq 0, \quad \forall y \in C
$$

and

$$
\phi\left(u_{n}, u_{n+1}\right)+\frac{1}{\beta_{n}}\left\langle u_{n+1}-u_{n}, u_{n}-x_{n}\right\rangle \geq 0, \quad \forall y \in C .
$$

So, from (A2), we have

$$
\left\langle u_{n+1}-u_{n}, \frac{u_{n}-x_{n}}{\beta_{n}}-\frac{u_{n+1}-x_{n+1}}{\beta_{n+1}}\right\rangle \geq 0,
$$

and hence

$$
\left\langle u_{n+1}-u_{n}, u_{n}-u_{n+1}+u_{n+1}-x_{n}-\frac{\beta_{n}}{\beta_{n+1}}\left(u_{n+1}-x_{n+1}\right)\right\rangle \geq 0
$$


Since $\lim _{n \rightarrow \infty} \beta_{n}>0$, without loss of generality, let us assume that there exists a real number $a$ such that $\beta_{n}>a>0$ for all $n \in \mathbb{N}$. Thus, we have

$$
\begin{aligned}
\left\|u_{n+1}-u_{n}\right\|^{2} & \leq\left\langle u_{n+1}-u_{n}, x_{n+1}-x_{n}+\left(1-\frac{\beta_{n}}{\beta_{n+1}}\right)\left(u_{n+1}-x_{n+1}\right)\right\rangle \\
& \leq\left\|u_{n+1}-u_{n}\right\|\left\{\left\|x_{n+1}-x_{n}\right\|+\left|1-\frac{\beta_{n}}{\beta_{n+1}}\right|\left\|u_{n+1}-x_{n+1}\right\|\right\},
\end{aligned}
$$

thus,

$$
\left\|u_{n+1}-u_{n}\right\| \leq\left\|x_{n+1}-x_{n}\right\|+\frac{1}{a}\left|\beta_{n+1}-\beta_{n}\right| M_{3},
$$

where $M_{3}=\sup \left\{\left\|u_{n}-x_{n}\right\|: n \in \mathbb{N}\right\}$.

From (3.6) and (3.9), we obtain

$$
\begin{aligned}
& \left\|x_{n+1}-x_{n}\right\| \\
& \quad \leq\left(1-\alpha_{n}(1-\rho)\right)\left\|x_{n}-x_{n-1}\right\|+M_{2}\left(\left|\alpha_{n}-\alpha_{n-1}\right|+\left|s_{n}-s_{n-1}\right|\right)+\left|\beta_{n}-\beta_{n-1}\right| \frac{M_{3}}{a} \\
& \quad \leq\left(1-\alpha_{n}(1-\rho)\right)\left\|x_{n}-x_{n-1}\right\|+M\left(\left|\alpha_{n}-\alpha_{n-1}\right|+\left|s_{n}-s_{n-1}\right|+\left|\beta_{n}-\beta_{n-1}\right|\right),
\end{aligned}
$$

where $M=\max \left[M_{2}, \frac{M_{3}}{a}\right]$. Hence, by Lemma 2.5 , we have

$$
\lim _{n \rightarrow \infty}\left\|x_{n+1}-x_{n}\right\|=0
$$

Then, from (3.9) and (3.10), and $\left|\beta_{n+1}-\beta_{n}\right| \rightarrow 0$, we have

$$
\lim _{n \rightarrow \infty}\left\|u_{n+1}-u_{n}\right\|=0
$$

For any $p \in U \cap \operatorname{EP}(\phi)$, as in the proof of Theorem 3.1, we have

$$
\left\|u_{n}-p\right\|^{2} \leq\left\|x_{n}-p\right\|^{2}-\left\|u_{n}-x_{n}\right\|^{2} .
$$

Then from (3.11), we derive that

$$
\begin{aligned}
\left\|x_{n+1}-p\right\|^{2}= & \left\|\alpha_{n} f\left(x_{n}\right)-\alpha_{n} p+\left(1-\alpha_{n}\right) T_{n} u_{n}-\left(1-\alpha_{n}\right) T_{n} p\right\|^{2} \\
\leq & \alpha_{n}^{2}\left\|f\left(x_{n}\right)-p\right\|^{2}+2 \alpha_{n}\left(1-\alpha_{n}\right)\left\|f\left(x_{n}\right)-p\right\|\left\|u_{n}-p\right\| \\
& +\left(1-\alpha_{n}\right)^{2}\left\|u_{n}-p\right\|^{2} \\
\leq & \alpha_{n}\left(\left\|f\left(x_{n}\right)-p\right\|^{2}+2\left\|f\left(x_{n}\right)-p\right\|\left\|u_{n}-p\right\|\right)+\left\|u_{n}-p\right\|^{2} \\
\leq & \left\|x_{n}-p\right\|^{2}-\left\|u_{n}-x_{n}\right\|^{2}+\alpha_{n}\left(\left\|f\left(x_{n}\right)-p\right\|^{2}\right. \\
& \left.+2\left\|f\left(x_{n}\right)-p\right\|\left\|u_{n}-p\right\|\right) .
\end{aligned}
$$

Since $\alpha_{n} \rightarrow 0$ and $\left\|x_{n}-x_{n+1}\right\| \rightarrow 0$, we have

$$
\lim _{n \rightarrow \infty}\left\|x_{n}-u_{n}\right\|=0
$$


Next, we have

$$
\begin{aligned}
\left\|x_{n}-T_{n} x_{n}\right\| & =\left\|\alpha_{n} f\left(x_{n}\right)+\left(1-\alpha_{n}\right) T_{n} u_{n}-T_{n} x_{n}\right\| \\
& \leq \alpha_{n}\left\|f\left(x_{n}\right)-T_{n} u_{n}\right\|+\left(1-\alpha_{n}\right)\left\|u_{n}-x_{n}\right\| .
\end{aligned}
$$

Then, $\left\|x_{n}-T_{n} x_{n}\right\| \rightarrow 0$, it follows that $\left\|u_{n}-T_{n} u_{n}\right\| \rightarrow 0$.

Now, we show that

$$
\limsup _{n \rightarrow \infty}\left\langle x_{n}-q,-(I-f) q\right\rangle \leq 0,
$$

where $q=P_{U \cap \operatorname{EP}(\phi)} f(q)$ is a unique solution of the variational inequality (3.1). Indeed, take a subsequence $\left\{x_{n_{k}}\right\}$ of $\left\{x_{n}\right\}$ such that

$$
\limsup _{n \rightarrow \infty}\left\langle x_{n}-q,-(I-f) q\right\rangle=\lim _{k \rightarrow \infty}\left\langle x_{n_{k}}-q,-(I-f) q\right\rangle .
$$

Since $\left\{x_{n}\right\}$ is bounded, without loss of generality, we may assume that $x_{n_{k}} \rightarrow \tilde{x}$. By the same argument as in the proof of Theorem 3.1, we have $\tilde{x} \in U \cap \operatorname{EP}(\phi)$.

Since $q=P_{U \cap \mathrm{EP}(\phi)} f(q)$, it follows that

$$
\limsup _{n \rightarrow \infty}\left\langle(I-f) q, q-x_{n}\right\rangle=\langle(I-f) q, q-\tilde{x}\rangle \leq 0
$$

From

$$
\begin{aligned}
x_{n+1}-q & =\alpha_{n} f\left(x_{n}\right)+\left(1-\alpha_{n}\right) T_{n} u_{n}-q \\
& =\alpha_{n} f\left(x_{n}\right)-\alpha_{n} f(q)+\alpha_{n} f(q)-\alpha_{n} q+\left(1-\alpha_{n}\right) T_{n} u_{n}-\left(1-\alpha_{n}\right) T_{n} q,
\end{aligned}
$$

we have

$$
\begin{aligned}
\left\|x_{n+1}-q\right\|^{2} & =\left\|\alpha_{n}\left(f\left(x_{n}\right)-f(q)\right)+\alpha_{n}(f(q)-q)+\left(1-\alpha_{n}\right)\left(T_{n} u_{n}-T_{n} q\right)\right\|^{2} \\
& \leq\left(1-\alpha_{n}\right)^{2}\left\|T_{n} u_{n}-T_{n} q\right\|^{2}+2 \alpha_{n}\left(f\left(x_{n}\right)-f(q)-(I-f) q, x_{n+1}-q\right\rangle .
\end{aligned}
$$

This implies that

$$
\begin{aligned}
\left\|x_{n+1}-q\right\|^{2} \leq & \left(1-\alpha_{n}\right)^{2}\left\|x_{n}-q\right\|^{2}+2 \alpha_{n} \rho\left\|x_{n}-q\right\|\left\|x_{n+1}-q\right\| \\
& +2 \alpha_{n}\left(-(I-f) q, x_{n+1}-q\right) \\
\leq & \left(1-\alpha_{n}\right)^{2}\left\|x_{n}-q\right\|^{2}+\alpha_{n} \rho\left(\left\|x_{n}-q\right\|^{2}+\left\|x_{n+1}-q\right\|^{2}\right) \\
& +2 \alpha_{n}\left(-(I-f) q, x_{n+1}-q\right) .
\end{aligned}
$$

Then, we have

$$
\begin{aligned}
\left\|x_{n+1}-q\right\|^{2} \leq & \frac{1-2 \alpha_{n}+\alpha_{n} \rho}{1-\alpha_{n} \rho}\left\|x_{n}-q\right\|^{2}+\frac{\alpha_{n}^{2}}{1-\alpha_{n} \rho}\left\|x_{n}-q\right\|^{2} \\
& +\frac{2 \alpha_{n}}{1-\alpha_{n} \rho}\left\langle-(I-f) q, x_{n+1}-q\right\rangle
\end{aligned}
$$




$$
\begin{aligned}
\leq & \left(1-2(1-\rho) \alpha_{n}\right)\left\|x_{n}-q\right\|^{2}+\frac{\alpha_{n}^{2}}{1-\alpha_{n} \rho}\left\|x_{n}-q\right\|^{2} \\
& +\frac{2 \alpha_{n}}{1-\alpha_{n} \rho}\left\langle-(I-f) q, x_{n+1}-q\right\rangle \\
\leq & \left(1-2(1-\rho) \alpha_{n}\right)\left\|x_{n}-q\right\|^{2}+2(1-\rho) \alpha_{n}\left(\frac{\alpha_{n}}{2(1-\rho)\left(1-\alpha_{n} \rho\right)} M^{*}\right. \\
& \left.+\frac{1}{(1-\rho)\left(1-\alpha_{n} \rho\right)}\left\langle-(I-f) q, x_{n+1}-q\right\rangle\right) \\
= & \left(1-2(1-\rho) \alpha_{n}\right)\left\|x_{n}-q\right\|^{2}+2(1-\rho) \alpha_{n} \delta_{n},
\end{aligned}
$$

where $M^{*}=\sup \left\{\left\|x_{n}-q\right\|^{2}: n \in \mathbb{N}\right\}$, and $\delta_{n}=\frac{\alpha_{n}}{2(1-\rho)\left(1-\alpha_{n} \rho\right)} M^{*}+\frac{1}{(1-\rho)\left(1-\alpha_{n} \rho\right)}\left\langle-(I-f) q, x_{n+1}-q\right\rangle$.

It is easy to see that $\lim _{n \rightarrow \infty} 2(1-\rho) \alpha_{n}=0, \sum_{n=1}^{\infty} 2(1-\rho) \alpha_{n}=\infty$, and $\limsup _{n \rightarrow \infty} \delta_{n} \leq 0$ by (3.12). Hence, by Lemma 2.5 , the sequence $\left\{x_{n}\right\}$ converges strongly to $q$. This completes the proof.

\section{Conclusions}

Methods for solving the equilibrium problem and the constrained convex minimization problem have extensively been studied respectively in a Hilbert space. But to the best of our knowledge, it would probably be the first time in the literature that we introduce implicit and explicit algorithms for finding the common element of the set of solutions of an equilibrium problem and the set of solutions of a constrained convex minimization problem, which also solves a certain variational inequality.

\section{Competing interests}

The authors declare that they have no competing interests.

\section{Authors' contributions}

All the authors read and approved the final manuscript.

\section{Acknowledgements}

The authors wish to thank the referees for their helpful comments, which notably improved the presentation of this manuscript. This work was supported in part by The Fundamental Research Funds for the Central Universities (the Special Fund of Science in Civil Aviation University of China: No. ZXH2012K001), and by the Science Research Foundation of Civil Aviation University of China (No. 2012KYM03).

Received: 20 March 2012 Accepted: 24 October 2012 Published: 7 November 2012

\section{References}

1. Mann, WR: Mean value methods in iteration. Proc. Am. Math. Soc. 4, 506-510 (1953)

2. Moudafi, A: Viscosity approximation method for fixed-points problems. J. Math. Anal. Appl. 241, 46-55 (2000)

3. Moudafi, A, Théra, M: Proximal and dynamical approaches to equilibrium problems. In: III-Posed Variational Problems and Regularization Techniques, Trier, 1998. Lecture Notes in Econom. and Math. System, vol. 477, pp. 187-201. Springer, Berlin (1999)

4. Ceng, LC, Al-Homidan, S, Ansari, QH, Yao, J-C: An iterative scheme for equilibrium problems and fixed point problems of strict pseudo-contraction mappings. J. Comput. Appl. Math. 223, 967-974 (2009)

5. Takahashi, S, Takahashi, W: Viscosity approximation methods for equilibrium problems and fixed point problems in Hilbert spaces. J. Math. Anal. Appl. 331, 506-515 (2007)

6. Tian, M: An application of hybrid steepest descent methods for equilibrium problems and strict pseudocontractions in Hilbert spaces. J. Inequal. Appl. 2011, Article ID 173430 (2011). doi:10.1155/2011/173430

7. Yamada, I: The hybrid steepest descent method for the variational inequality problem over the intersection of fixed point sets of nonexpansive mappings. In: Inherently Parallel Algorithms in Feasibility and Optimization and Their Application, Haifa (2001)

8. Liu, Y: A general iterative method for equilibrium problems and strict pseudo-contractions in Hilbert spaces. Nonlinear Anal. 71, 4852-4861 (2009)

9. Plubtieng, S, Punpaeng, R: A general iterative method for equilibrium problems and fixed point problems in Hilbert space. J. Math. Anal. Appl. 336, 455-469 (2007)

10. Jung, JS: Strong convergence of iterative methods for k-strictly pseudo-contractive mappings in Hilbert spaces. Appl. Math. Comput. 215, 3746-3753 (2010) 
11. Jung, JS: Strong convergence of composite iterative methods for equilibrium problems and fixed point problems. Appl. Math. Comput. 213, 498-505 (2009)

12. Kumam, P: A new hybrid iterative method for solution of equilibrium problems and fixed point problems for an inverse strongly monotone operator and a nonexpansive mapping. J. Appl. Math. Comput. 29, 263-280 (2009)

13. Kumam, P: A hybrid approximation method for equilibrium and fixed point problems for a monotone mapping and a nonexpansive mapping. Nonlinear Anal. Hybrid Syst. 2(4), 1245-1255 (2008)

14. Saewan, $S$, Kumam, P: The shrinking projection method for solving generalized equilibrium problem and common fixed points for asymptotically quasi- $\phi$-nonexpansive mappings. Fixed Point Theory Appl. (2011) doi:10.1186/1687-1812-2011-9

15. Tada, A, Takahashi, W: Weak and strong convergence theorems for a nonexpansive mapping and an equilibrium problem. J. Optim. Theory Appl. 133, 359-370 (2007)

16. Yao, Y, Liou, YC, Yao, JC: Convergence theorem for equilibrium problems and fixed point problems of infinite family of nonexpansive mappings. Fixed Point Theory Appl. 2007, Article ID 64363 (2007)

17. Su, YF, Shang, MJ, Qin, XL: An iterative method of solution for equilibrium and optimization problems. Nonlinear Anal., Theory Methods Appl. 69, 2709-2719 (2008)

18. Plubtieng, S, Punpaeng, R: A new iterative method for equilibrium problems and fixed point problems of nonlinear mappings and monotone mappings. Appl. Math. Comput. 179, 548-558 (2008)

19. Xu, HK: Averaged mappings and the gradient-projection algorithm. J. Optim. Theory Appl. 150, 360-378 (2011)

20. Xu, HK: An iterative approach to quadratic optimization. J. Optim. Theory Appl. 116, 659-678 (2003)

21. Xu, HK: Iterative algorithms for nonlinear operators. J. Lond. Math. Soc. 66, 240-256 (2002)

22. Ceng, LC, Ansari, $\mathrm{QH}$, Yao, J-C: Some iterative methods for finding fixed points and for solving constrained convex minimization problems. Nonlinear Anal. 74, 5286-5302 (2011)

23. Marino, G, Xu, HK: A general method for nonexpansive mappings in Hilbert space. J. Math. Anal. Appl. 318, 43-52 (2006)

24. Xu, HK: Viscosity approximation methods for nonexpansive mappings. J. Math. Anal. Appl. 298, 279-291 (2004)

25. Bkun, E, Oettli, W: From optimization and variational inequalities to equilibrium problems. Math. Stud. 63, 123-145 (1994)

26. Combettes, PL, Hirstoaga, SA: Equilibrium programming in Hilbert spaces. J. Nonlinear Convex Anal. 6, 117-136 (2005)

27. Byrne, C: A unified treatment of some iterative algorithms in signal processing and image reconstruction. Inverse Probl. 20, 103-120 (2004)

28. Geobel, K, Kirk, WA: Topics on Metric Fixed Points Theory. Cambridge Studies in Advanced Mathematical, vol. 28. Cambridge University Press, Cambridge (1990)

29. Bretarkas, DP, Gafin, EM: Projection methods for variational inequalities with applications to the traffic assignment problem. Math. Program. Stud. 17, 139-159 (1982)

30. Han, D, Lo, HK: Solving non additive traffic assignment problems: a descent method for cocoercive variational inequalities. Eur. J. Oper. Res. 159, 529-544 (2004)

doi:10.1186/1687-1812-2012-201

Cite this article as: Tian and Liu: Iterative algorithms based on the viscosity approximation method for equilibrium and constrained convex minimization problem. Fixed Point Theory and Applications 2012 2012:201.

\section{Submit your manuscript to a SpringerOpen ${ }^{\circ}$ journal and benefit from:}

- Convenient online submission

Rigorous peer review

- Immediate publication on acceptance

- Open access: articles freely available online

- High visibility within the field

- Retaining the copyright to your article 